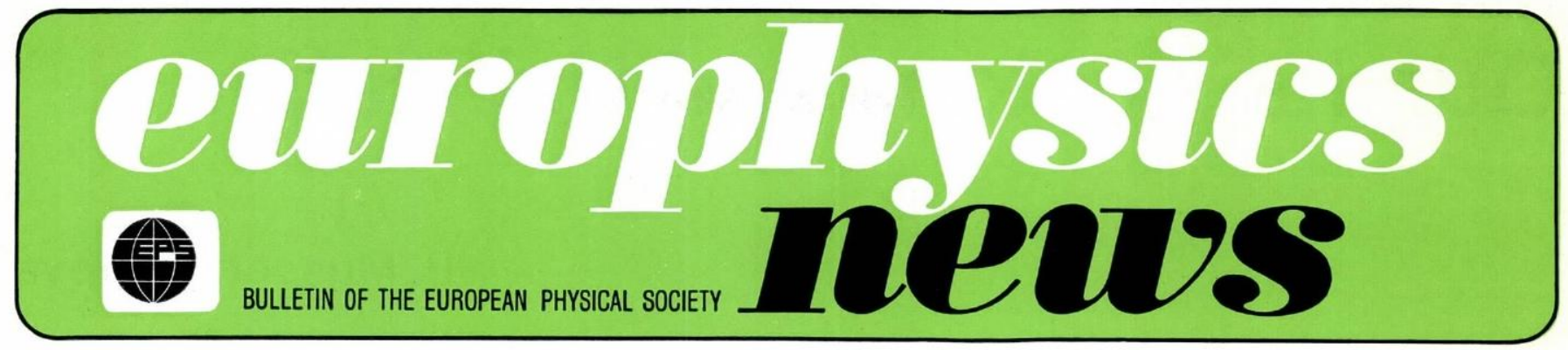

J.A. Volume $9 \quad$ Number 9

September 1978

September 26 marks the 10th anniversary of the foundation of the European Physical Society

Over the past ten years, the European Physical Society has firmly established itself as the European forum for physics, bringing together all the disciplines and providing a common ground for discussion. We have a structure on which we can build for the future.

As we look forward though, we must have a vision of why we are striving and what we hope to achieve. We all accept that our broad objective is to enhance the culture of the world into which we were brought and that a major contribution to this culture is to unite people around a common understanding; for us, this understanding is of physics. And let us not forget that physics is no minor aspect of our culture but is fundamental to it. We have no need to be embarrassed at having such ideals; they are essential if we are to know how to move forward. One can always find reasons for standing still, for looking back on what has been done. Especially is this true when people of diverse culture, religion and political structure are to cooperate.

There are always differences to be found between peoples and organizations - our rôle is to seek out the opportunities for unity and concentrate on these, not on the difficulties that might arise. We must also resist the temptation to shut ourselves into compartments. EPS is a Society for all physicists where they can interact to their mutual benefit.

We have, for example, in Europe at present a number of major projects under development that concern the whole physics community not just the separate specialists in each field. Five that come to mind are: the electronpositron colliding beam facility, that could involve collaboration also with

\title{
The Next Ten Years
}

Summary of an interview with the President of EPS, Antonino Zichichi

other continents; the fixed target super proton synchrotron of about $1 \mathrm{TeV}$ that is being considered in the USSR; the European synchrotron radiation source; JET; the millimetre wavelength radio-inferometer. EPS must play a part in the evolution of these projects - of coordination and analysis, even of promoting simple awareness. This is why EPS is organizing a symposium in conjunction with our Council meeting in Rome next March, where these projects can be presented. Also it is right that when we assemble physicists from all over Europe, from so many disciplines, that it is not only business we discuss.

Earlier on we talked of culture. Now the centre of our cultural development is the Universities and the emerging generation. This is why the core of EPS itself is inevitably the academic world - in no way to the exclusion of any group of physicists of other callings, but simply because a dynamic science radiates out from the academic centre. It is evident therefore that EPS must take an active role in the creation of new European academic scientific and technical institutions. For example, EPS must be prepared to participate in discussions concerning the European University for pure science and the Mediterranean region Polytechnic that looks particularly towards the developing countries and so leans towards the earth and life sciences and applied problems. Such joint institutions present a great challenge. Europe is both divided by and enriched by the separate languages and cultures of its members. We must concentrate on the enrichment while still seeking unity in the practical aspects, harmonizing levels of qualification, for example, and developing the best teaching practices. We are all part of a new Europe, and we have a duty to contribute to the creation of new European institutions that meet the needs not just of today, but the longterm future as well.

At the same time we must not be insular obessed by local problems, regarding Europe as an isolated corner of the world. Rather do we have to be ready to cooperate with our colleagues in other continents. We all suffer from the concept of a world composed of faceless masses, instead of people. Communication is the key to these people becoming real, the key to mutual understanding from which can develop mutual tolerance. Physics is a field in which we can and should communicate as part of our contribution to a world society. A World Physical Society is something that we should move towards, therefore, regardless of any current difficulties that might beset us.

In setting our sights on these longterm aims we must not, of course, forget the day-to-day activities of our Society that are vital to its well-being. The work of organizing and coordinating conferences, for example, is a basic necessity, the continuous efforts to improve the publishing scene, of great significance as well as complexity. These are fundamental preoccupations. Of the latest initiatives, the scholarship and visiting professor schemes, are also of great importance. Now having made a modest start, the schemes must be widened and made to be more representative of all Europe. An established matrix of scholarships and professional posts throughout our members would have a tremendous impact on both the coming generation of physicists and on their institutions. 